\title{
Painful snapping hip owing to bifid iliopsoas tendon and concurrent labral tear
}

\author{
Author: \\ Graeme Thompson ${ }^{1}$ \\ Affiliation: \\ ${ }^{1}$ Morton and Partners, Cape \\ Town, South Africa \\ Correspondence to: \\ Graeme Thompson \\ Email: \\ gt@morton.co.za \\ Postal address: \\ 20A Brommaert Avenue, \\ Constantia 7806, Cape Town, \\ South Africa \\ Dates: \\ Received: 06 Oct. 2014 \\ Accepted: 22 Feb. 2015 \\ Published: 22 May 2015 \\ How to cite this article: \\ Thompson, G. Painful \\ snapping hip owing to \\ bifid iliopsoas tendon and \\ concurrent labral tear. $S$ \\ Afr J Rad. 2015;19(1); Art. \\ \#741, 2 pages. http://dx.doi. \\ org/10.4102/sajr.v19i1.741 \\ Copyright: \\ (C) 2015. The Authors. \\ Licensee: AOSIS \\ OpenJournals. This work is \\ licensed under the Creative \\ Commons Attribution \\ License.
}

Read online:

Scan this QR code with your smart phone or mobile device to read online.
A case of internal snapping hip owing to a bifid iliopsoas tendon is described with a concurrent labral tear in a young active female. The labral tear was identified on magnetic resonance imaging, and the snapping bifid tendon on dynamic ultrasound. The patient was administered bupivicaine and steroid around the tendon and symptoms resolved. A snapping bifid tendon must be identified pre-operatively to avoid incomplete release. Labral repair may be accompanied by psoas release when psoas impingement is suspected owing to a labral tear at the 3 o'clock position in an otherwise normal hip.

\section{Introduction}

Painful snapping hip or coxa sultans is a condition seen in young active patients. This report presents the features of a snapping bifid iliopsoas tendon and discusses the potential relationship of the psoas tendon to anterior labral tears.

\section{Case presentation}

A 20-year-old, physically active female presented with a painful, snapping right hip. Clinical tests for impingement were negative and the patient had a full range of movement. Magnetic resonance imaging (MRI) of the right hip showed a bifid psoas tendon (Figure 1) but no abnormal tendon signal or bursitis. MRI also revealed a full thickness labral detachment confined to the anterior 3 o'clock position, deep to the iliopsoas tendon (Figure 2).

The femoro-acetabular morphology was normal. A dynamic ultrasound of the iliopsoas tendon was performed at the same appointment with an audible snap occurring whilst the patient returned the leg from flexion, abduction and external rotation or the frog-leg position (Figure 3) to neutral (Figure 4). The snap occurred as the medial component of the bifid tendon (which had rolled laterally over the lateral component during the frog-leg manoeuvre) returned abruptly over the lateral component to its original position, striking the superior pubic ramus. The referring surgeon elected to treat the patient conservatively with a bupivicaine and steroid injection under the bifid iliopsoas tendon, that produced symptomatic relief.

\section{Discussion}

A painful snapping hip is typically seen in young athletic individuals such as ballet dancers. ${ }^{1}$ Intra-articular causes include labral tears or loose bodies. Extra-articular causes are classified as internal due to iliopsoas, or external secondary to conflict of the iliotibial band and gluteus maximus with the greater trochanter. ${ }^{2}$ Deslandes et al. ${ }^{3}$ demonstrated sonographically that most cases of internal snapping hip result from the dynamic relationship of the iliopsoas tendon with the muscle belly and pubic ramus. Three of the snapping hips they studied were, as in the present case, because of a bifid tendon with the mechanism described above in the case presentation. The importance of this finding is that the bifid tendon must be identified pre-operatively to avoid persistence of symptoms owing to incomplete arthroscopic release. ${ }^{4}$

Also of interest in the present case is the possible relationship of the psoas tendon to labral tears or 'psoas impingement'. Cascio et al..$^{5}$ found a subset of patients at arthroscopy with normal femoro-acetabular morphology and labral tears confined to the 3 o'clock position, underlying the psoas tendon. These patients were treated with labral repair and psoas release, with good results. The mechanism of this relationship is unknown but one postulate is traction on the hip capsulo-labral complex by a tight psoas tendon. The patient in this case responded to a psoas injection, and the snapping iliopsoas is the presumed aetiology of symptoms but, in a patient with otherwise normal hip morphology, a labral tear confined to between the 2 and 3 o'clock positions should prompt the suggestion of psoas impingement, with a lateral dip of the tendon as supporting evidence in some cases. ${ }^{6}$ 


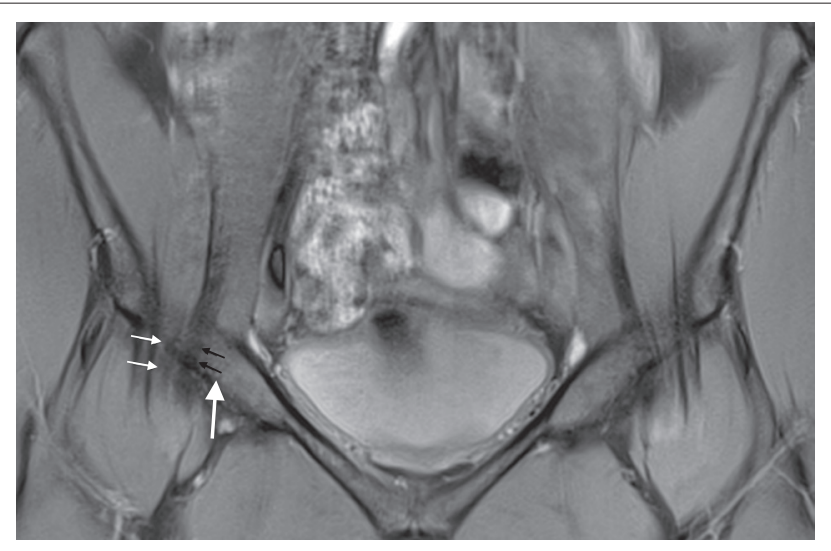

FIGURE 1: Coronal proton density fat saturation (PDFS) image of the pelvis shows a bifid iliopsoas tendon on the right with medial (short black arrows) and lateral (short white arrows) components. The inferior edge of the superior pubic ramus is also shown (long white arrow).

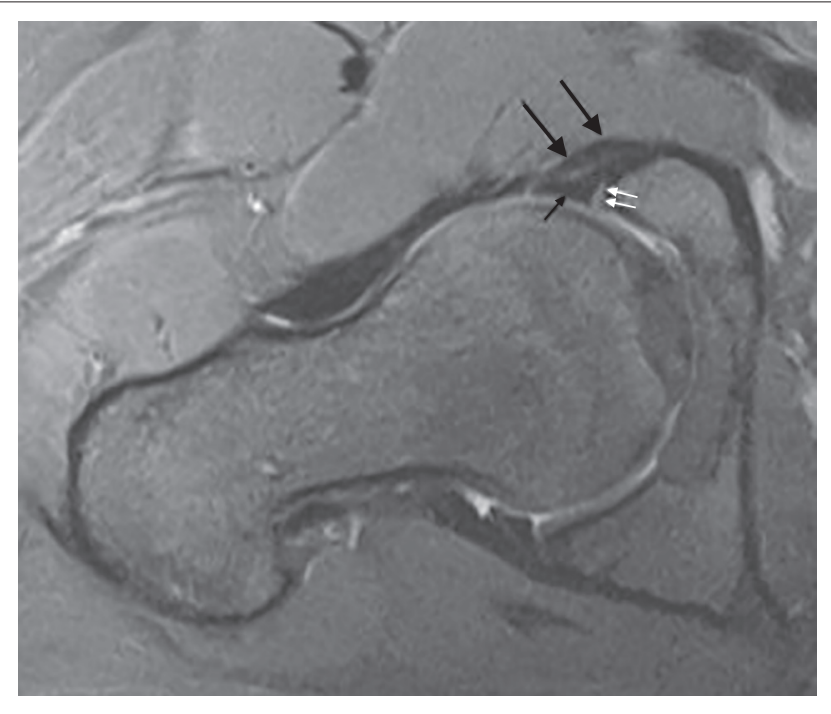

FIGURE 2: Axial oblique PDFS image of the right hip. Detachment (short white arrows) of the anterior labrum (short black arrow) which on consecutive images was full thickness. The overlying psoas tendon (long black arrows) 'dips' laterally, raising suspicion of psoas impingement.

\section{Conclusion}

The present case highlights an unusual cause of internal snapping hip of which the surgeon should be made aware pre-operatively to avoid incomplete psoas release. Moreover, the possibility of psoas impingement as a contributor to a labral tear must be raised when the tear is confined to between the 2 and 3 o'clock positions.

\section{Acknowledgements Competing interests}

The author declares that he has no financial or personal relationship(s) that may have inappropriately influenced them in writing this article.

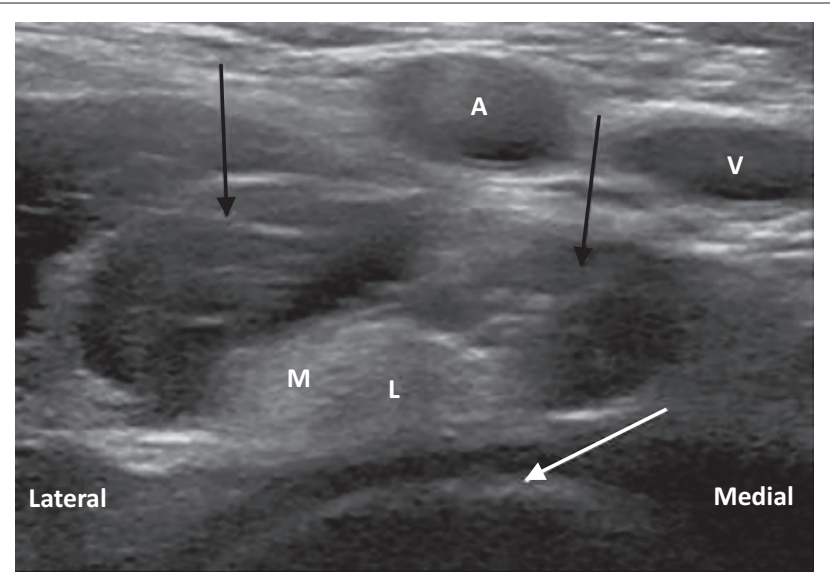

FIGURE 3: Axial ultrasound image with the patient beginning to return to neutral from the frog-leg position. The medial psoas tendon component (M) lies anterolateral to the lateral component (L). The iliopsoas muscle (long black arrows) and femoral head (long white arrow) are shown on this image just below the acetabular rim.

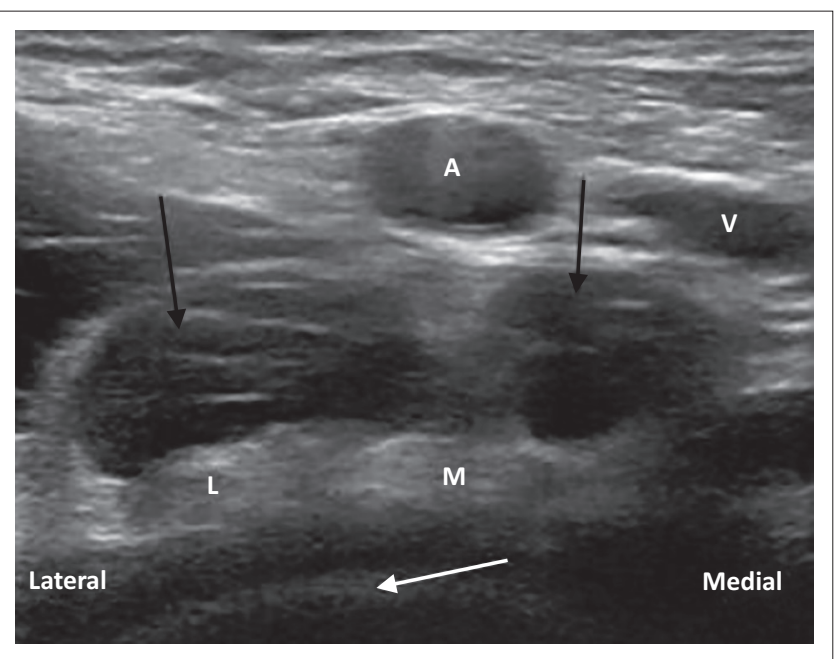

FIGURE 4: At the same level as in Figure 3 but with the leg in the neutra position, the medial tendon $(\mathrm{M})$ has returned with a snap to lie medially against the acetabular rim in its normal position relative to the lateral tendon (L).

\section{References}

1. Howse AJG. Orthopaedists aid ballet. Clin Orthop Relat Res. 1972;89:52-63.

2. Pelsser V, Cardinal E, Hobden R, Aubin B, Lafortune M. Extraarticular snapping hip: sonographic findings. AJR. 2001;176:67-73.

3. Deslandes M, Guillin R, Cardinal E, Hobden R, Bureau NJ. The snapping iliopsoas tendon: new mechanisms using dynamic sonography. AJR. 2008;190: 576-581.

4. Shu B, Safran MR. Case report: bifid iliopsoas tendon causing refractory internal snapping hip. Clin Orthop Relat Res. 2011;469:289-293.

5. Cascio BM, King D, Yen YM. Psoas impingement causing labrum tear: a series from three tertiary hip arthroscopy centers. J La State Med Soc. 2013;165: 88-93.

6. Blankenbaker DG, Tuite MJ, Keene JS, del Rio AM. Labral injuries due to iliopsoas impingement: can they be diagnosed on MR arthrography? AJR. 2012;199: 894-900. 